\title{
Biliary Motility: Postnatal Changes in Guinea Pigs
}

\author{
KENNETH L. COX, ANTHONY T. W. CHEUNG, CARLETON L. LOHSE, ERIN M. WALSH, AND \\ CHRISTINE K. IWAHASHI-HOSODA \\ Departments of Pediatrics and Veterinary Medical Anatomy and Primate Center, University of California, \\ Davis, California 95616
}

\begin{abstract}
Intravital microscopy, a new in vivo technique, documented age-dependent changes in choledochoduodenal junction motility in male guinea pigs. In the guinea pig, the choledochoduodenal junction served as a pump that actively emptied its luminal contents into the duodenum. In the neonates ( $\leq 1$ wk old), this choledochoduodenal junction pump was not fully developed. Unlike the older guinea pigs, some neonates had an incompetent sphincter ductus choledochi (SDC) allowing retrograde flow of bile during ampullary contractions. While fasting, neonates had decreased frequency of SDC $(1.2 \pm 0.4$ contractions/min) and ampullary $(0.1 \pm 0.1$ contractions/ min) contractions as compared to juveniles (4-6 wk old) $(\mathrm{SDC}=6.4 \pm 1.0 ;$ ampulla $=1.2 \pm 0.2$ contractions $/ \mathrm{min})$ and adults $(>1$ yr old $)($ SDC $=6.7 \pm 1.6 ; 0.8 \pm 0.2$ contractions/min). Following a meal (Ensure), unlike older guinea pigs, the neonate did not have a significant increased duration and decreased frequency of SDC contractions. Altered neonatal SDC motility correlated with an incompletely developed SDC including decreased muscle mass and mucosal thickness. By 4 wk of age, choledochoduodenal junction motility was similar to that of the adult. These developmental alterations in junctional motility and structure may affect the flow of bile into the duodenum contributing to physiologic cholestasis and decreased intraduodenal bile acids seen in neonates. (Pediatr Res 21: 170175, 1987)
\end{abstract}

\section{Abbreviations}

SDC, sphincter ductur choledochi

CDJ, choledochoduodenal junction

CCK, cholecystokinin

As compared to the adult, the human newborn is cholestatic and has a reduced bile acid pool size (1-7). This "physiologic" neonatal cholestasis has been attributed to: 1) pertubations of hepatic hemodynamics, 2) decreases in liver uptake, transport, and excretion of bile acids resulting in decreased bile flow, 3) atypical bile acids such as lithocholic acid, and 4) reduced ileal transport of bile acids $(3,6,8-14)$. Between 2 and $3 \mathrm{wk}$ postnatally in humans and guinea pigs, the bile-acid pool size significantly increases providing more bile acids to facilitate fat digestion and absorption $(15,16)$. Watkins and coworkers postulated that this increase is due to growth and maturation of the biliary

Received June 4, 1986: accepted September 25. 1986.

Correspondence and requests for reprints to Kenneth L. Cox, M.D., TB 138 , Department of Pediatrics, University of California, Davis, Davis, CA 95616.

Supported by a National Institutes of Health Grant RR00169 and a Biomedical Research Support Grant awarded to UC Davis School of Medicine. tract stimulated by factors in breast milk $(17,18)$. Thus, biliary tract maturation occurs postnatally and may be influenced by the diet.

The role of maturational changes in biliary motility and structure in neonatal cholestasis and reduced intraduodenal bile acids has not been studied. The flow of bile acids into the duodenum is dependent on gallbladder contraction and passage through the CDJ. In vitro gallbladder bioassays of fetal and neonatal guinea pig gallbladders have been responsive to cholinergic and CCK stimulation. The maximal stimulated tension of the gallbladders were shown to increase postnatally (19). This suggested that receptors for regulating gallbladder contraction were present and functioning in the neonate, but the number of functioning receptors were decreased and/or the gallbladder muscle was less responsive. In newborn piglets, in vivo gallbladders also were responsive to cholinergic and CCK stimulation, but were less compliant than adult gallbladders (20). This altered compliance has been implicated as a possible cause of neontal cholestasis. The postulated mechanism is that the contractility of the neonatal gallbladder is insufficient to generate intraluminal pressures needed to overcome resistances produced by the common bile duct and the CDJ.

However, until recently, the motility and structure of the bile duct and the CDJ in neonates have not been determined. Using morphometric analysis of serial histologic sections (21), we recently quantitated postnatal changes in biliary structures in guinea piges (22). As compared to juveniles (4-6 wk old) and adults $(>1$ yr old), neonatal ( $\leq 1$ wk old) guinea pigs had decreased amounts of smooth muscle and mucosa in the SDC, a component of the CDJ. Since the CDJ influences bile flow and gallbladder emptying, these maturational changes may be important factors in causing cholestasis and decreased intraduodenal bile salts in neonates.

The purpose of this study was to utilize intravital microscopy, a new, sensitive in vivo technique $(23,24)$, to determine the developmental changes in biliary motility in guinea pigs and to correlate motility with structure and bile flow rates.

\section{MATERIALS AND METHODS}

Three age groups of male Hartley guinea pigs were studied. These were: 1) 1 to 7 days old (80-100 g), 2) 4- to 6-wk-old juveniles (300-400 g), and 3) adults more than 1 yr old (900$1200 \mathrm{~g})$

Intravital microscopy was performed on 10 neonates, 20 juveniles, and 10 adults $(23,24)$. They were fasted overnight with ad libitum water and studies were begun at $0800 \mathrm{~h}$. The animals were anesthetized with an intramuscular injection of ketamine (Vetalar, Parke Davis Lab., Morris Plains, NJ) $100 \mathrm{mg} / \mathrm{kg}$, xylazine (Rompun, Haver-Lockhart, Shawnee, KS) $5 \mathrm{mg} / \mathrm{kg}$, and acepromazine (PromAce, Fort Dodge Lab., Fort Dodge, IA) $4 \mathrm{mg} / \mathrm{kg}$. During the studies, one-half of each dose of anesthetics 
was given when the animal became responsive to stimulation. A central venous line was placed in the external jugular vein and through this catheter normal saline was infused at $0.025 \mathrm{ml} / \mathrm{kg} /$ min to maintain hydration. A thermostated heat curtain and a heating pad were used to maintain body temperatures. A laparotomy exposed the biliary tract. The intestine was covered with gauze moistened with normal saline. Special care was taken not to disturb the bile duct and neighboring tissues. This insured minimal trauma imparted to the duct and tissues to be investigated.

A 22-gauge catheter (Jelco, Critikon, Tampa, FL) was inserted through the overlying chest wall into the gallbladder. The needle was removed from the catheter and a " $T$ " connector (Extension set with "T", Abbott, Inc., Chicago, IL) was inserted into the end of the catheter. This provided a site where bile could be aspirated and fluorescent tracers injected without manipulating the biliary tract.

Utilizing Leitz ultrapack optics (for a 40- to 80-fold magnification) and epifluorescence irradiation (reflected light at a wavelength capable of activating the fluorescent tracer) activated by a $100 \mathrm{~W}$ Mercury arc source, the intravital microscope was adapted to visualize and document movement of fluorescent tracers (Nafluorescein) with the assistance of a low-light level Dage S.I.T. video camera $(23,24)$. Biliary motility and related activities were viewed on a Sony television screen and documented on videotape using a JVC (model $\mathrm{Cr} 6060 \mathrm{U}$ ) $3 / 4$ inch cassette video recorder. The area of the biliary tract observed is shown in Figure 1. The videotapes were later analyzed for frequency and duration of ampullary and SDC contractions.

Using epiillumination (reflected light from a standard light source) to establish baseline motility, the frequency and duration of SDC and ampullary contractions were quantitated for at least $15 \mathrm{~min}$ before injecting the fluorescein. Bile $(0.3 \mathrm{ml})$ was aspirated through the " $T$ " connector and $0.3 \mathrm{ml}$ of $25 \%$ Na fluorescein (AK-Fluor-25, Akorn Inc., Metairie, LA) was injected through the " $T$ " connector into the gallbladder. For at least $1 \mathrm{~h}$ after injecting the fluorescein, the bile was uniformly fluorescent and fully illuminated the lumen of the biliary tract; thus improving the visualization of contractions and bile flow characteristics. Segmental changes in lumen diameter indicated contraction.

As controls, 10 fasting juveniles were studied without meal stimulation for $15 \mathrm{~min}$ both before and $1 \mathrm{hr}$ after injecting the fluorescein. In these animals, the frequency and duration of SDC and ampullary contractions were quantitated at 15 -min intervals.

After injecting the fluorescein in 10 animals in each age group, the frequency and duration of SDC and ampullary contractions were quantitated for $15 \mathrm{~min}$ while fasting and at 15 -min intervals for $45 \mathrm{~min}$ after injecting $10 \mathrm{ml} / \mathrm{kg}$ of a liquid meal (Ensure: protein $3.7 \mathrm{~g} / \mathrm{dl}$, fat $3.7 \mathrm{~g} / \mathrm{dl}$, carbohydrate $14.3 \mathrm{~g} / \mathrm{dl}$, and calories $106 / \mathrm{dl}$ ) into the duodenum.

The frequency (number of contractions per min) and duration ( $m$ s that the lumen's diameter was narrowed) of contractions were quantitated visually using a digital clock on the television monitor and a mm ruler.

To evaluate the results of intravital microscopy, biliary manometry was performed on 20 Hartley male guinea pigs (weighing 250 to $500 \mathrm{~g}$ ). Animals were prepared as described above for intravital microscopy. In 10 animals, an incision in the ventral duodenal wall exposed the papilla. Two catheters (each with $0.28-\mathrm{mm}$ internal diameter for $8 \mathrm{~cm}$ and flared to $2 \mathrm{~mm}$ internal diameter for $12 \mathrm{~cm}$ ) were passed through the papilla positioning the perfused side opening of one catheter in the SDC and the other in the ampulla. In the other 10 animals, these two catheters were passed through the gallbladder, cystic duct, and bile duct positioning one port in the SDC and the other in the ampulla. The catheters were perfused at $0.07 \mathrm{ml} / \mathrm{min}$ with water at 4 PSI using a pneumohydraulic pump. Pressure changes within the perfusion system were recorded via Statham transducers on a Beckman R511A recording system using type 9877 transducer couplers, type $461 \mathrm{D}$ preamplifier, and type 411 amplifier. For these manometric studies, the reference pressure for zero was atmospheric pressure, during infusion the baseline resistance ranged from 5 to $15 \mathrm{~mm} \mathrm{Hg}$ and was set to zero, and before each study the system was calibrated with a manometer.

Fasting bile flow rates in 10 guinea pigs from each age group were quantitated by measuring the volume of bile collected from bile duct above the SDC. An incision in the ventral duodenal wall exposed the papilla. The cystic duct was ligated with a 5-0 silk ligature. A polyethylene tube (Intramedic PE-50, OD 0.965 $\mathrm{mm}$ ) was inserted through the papilla and ampulla into the bile duct. It was positioned so that the tip was above the SDC. A 40 silk ligature was tied around the duct and cannula to prevent

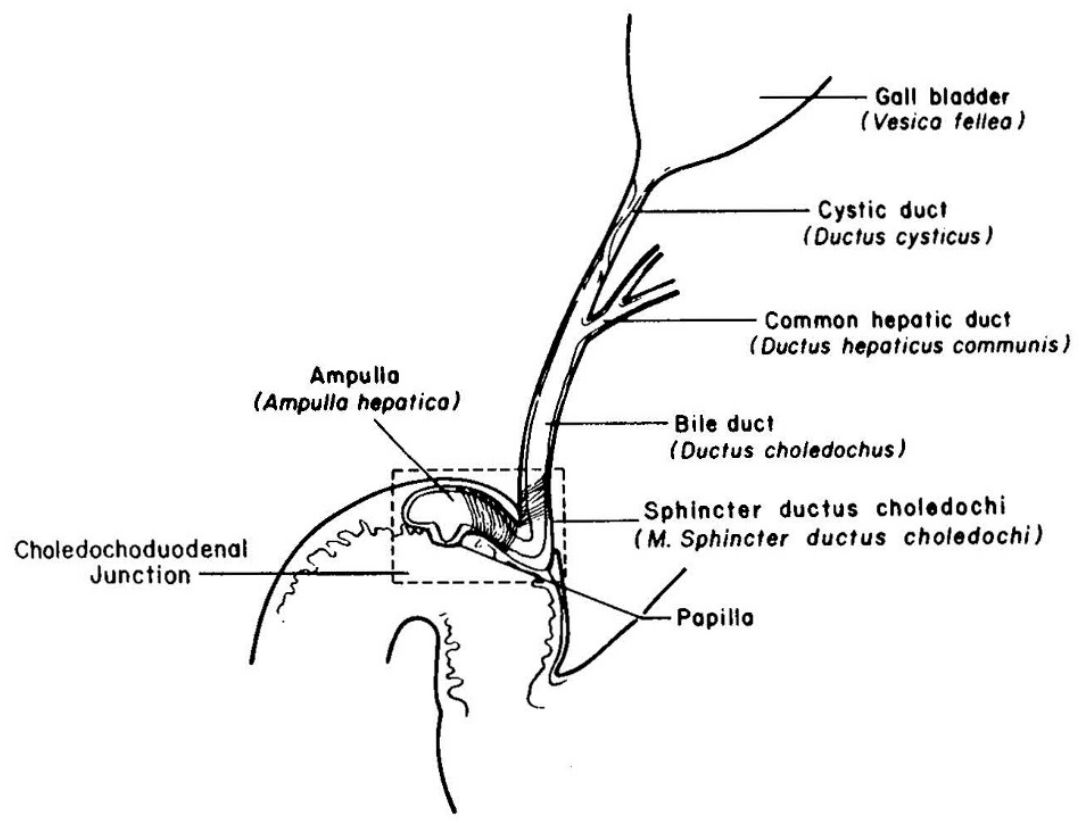

Fig. 1. Diagram of extrahepatic biliary tract in guinea pigs. The choledochoduodenal junction, the area within the box, is the region of the biliary tract observed during intravital microscopy. In guinea pigs the pancreatic duct enters the duodenum at a location several $\mathrm{cm}$ distal from the biliary tract (24). 
leakage around the cannula. At 10 -min intervals for $60 \mathrm{~min}$, the volume of bile collected from the catheter was measured and emptied into the duodenum distal to the papilla. Bile flow rates were measured in $\mu \mathrm{l} / \mathrm{min}, \mu \mathrm{l} / \mathrm{kg}$ of body weight $/ \mathrm{min}$, and $\mu \mathrm{l} / 10$ $\mathrm{g}$ of liver/min to determine the influences of body weight.

All data are expressed with SEM. Data were analyzed for statistical significance using Students $t$ tests and analysis of variance.

\section{RESULTS}

In the neonates, the frequencies of SDC and ampullary contractions were lower when compared with older guinea pigs (Fig. 1). Postprandially, in the older guinea pigs ( $\geq 4$ wk of age), there were increases in duration and decreases in frequency of SDC contraction while in the neonate SDC motility did not change significantly. The large SEMs in duration of SDC contractions in the neonate indicated the variability in motility patterns in this age group. In all age groups, the frequency of ampullary contractions increased postprandially (Fig. 2). However, this increase was significant only in the neonates. The juvenile and adult guinea pigs had similar SDC and ampullary motility parameters, except that postprandially the duration of ampullary contractions were greater in the juveniles. In all age groups, the SDC had greater frequency and shorter duration of contractions as compared to the ampulla.

There was a spectrum of motility patterns seen in the neonates; 1) no ampullary or SDC motility $(n=2), 2)$ reduced frequency of ampullary and SDC contractions with the latter being incomplete (did not competely occlude the lumen of the SDC) $(n=6)$, and 3)normal ampullary and SDC contractions except for reduced frequency $(n=2)$. There was no correlation between motility pattern and days of age.

In the neonates, SDC contractions often did not completely occlude the lumen (Fig. $3 A$ ) resulting in retrograde flow of bile into the duct during ampullary contractions. The fold (" $f$ " in Fig. 3) separating the SDC and ampulla prevented the flow of bile into the ampulla until the lumen of the SDC had filled forming a triangular shape (Fig. $3 B$ and $C$ ).

In contrast to the neonate, the guinea pigs which were beyond $4 \mathrm{wk}$ of age had complete closure of the SDC during contractions and this closure prevented retrograde flow of bile during ampullary contractions (Fig. $4 A$ ). In these older guinea pigs, intravital microscopy documented rhythmic asymmetrical contractions of the SDC which most often occurred independent of ampullary contractions (Fig. $4 B$ ). During relaxation of the SDC, bile filled the lumen of the SDC and flowed around the fold separating the SDC and ampulla into the ampulla (Fig. 4C). Following several contractions of the SDC, the filled ampulla had a milking contraction emptying its bile into the duodenum. Simultaneous SDC contraction prevented retrograde flow of bile during ampullary contractions. After an ampullary contraction, the time until the next SDC contraction was usually longer than subsequent intervals between SDC contractions. The fold separating the SDC from the ampulla limited the flow from the relaxed SDC.

At all ages, the diameter of the bile duct decreased as it was stretched toward the duodenum during ampullary and/or SDC contractions. There was no evidence of peristaltic movements in the bile duct.

In all animals, intravital microscopy was performed without complication. There were no changes in frequency and duration of SDC and ampullary contractions in 15-min intervals for the $15 \mathrm{~min}$ before and for the $1 \mathrm{~h}$ after injecting the fluorescein in the 10 juvenile controls. We carefully avoided manipulating the duct as we noticed that touching the CDJ with a probe could decrease or eliminate motility as long as $60 \mathrm{~min}$. Fifty percent of animals became responsive to painful stimuli during the study and, therefore, received additional doses of anesthetics. There was no changes in biliary motility associated with responsiveness to stimulation or dose of anesthetic administered.
SDC

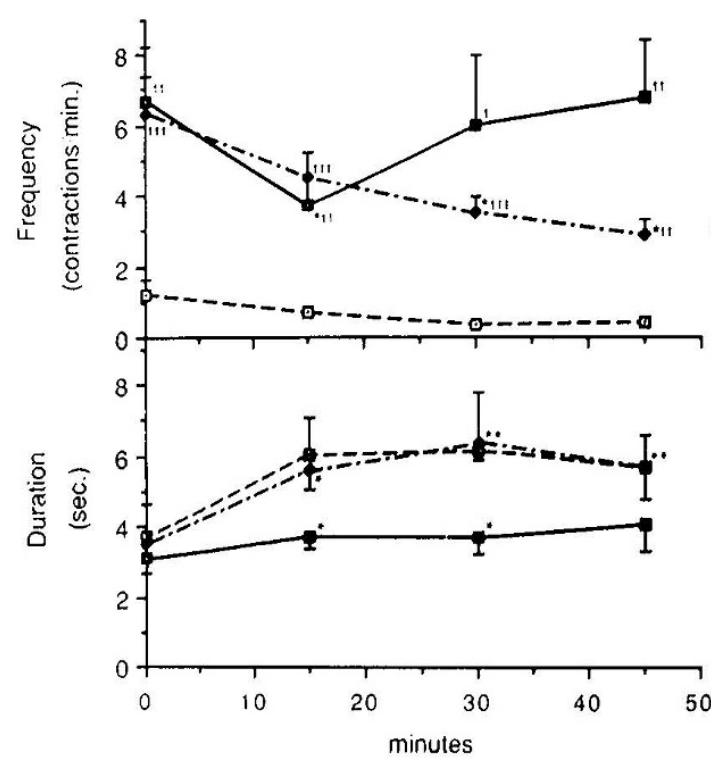

D $<1$ week

- 4.6 weeks

- $<1$ year
AMPULLARY

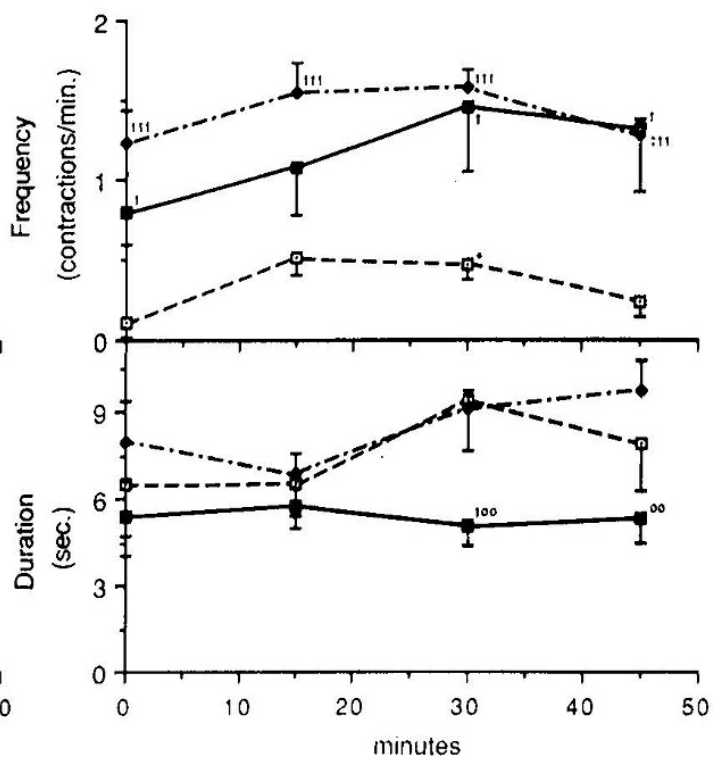

Fig. 2. Age-dependent differences in fasting and meal-stimulated SDC and ampullary motility. Each time point represent the average ( \pm SEM) frequency or duration of contractions over of the preceding 15 -min interval for 10 guinea pigs. At 0 time, $10 \mathrm{ml} / \mathrm{kg}$ of Ensure was injected into the duodenum. ${ }^{*} p<0.05$ and ${ }^{* *} p<0.01$ compared to fasting; ${ }^{+} p<0.05,{ }^{++} p<0.01$, and ${ }^{+++} p<0.001$ compared to the newborns; ${ }^{\circ} p<0.05$ and ${ }^{\circ} p<0.01$ compared to the juveniles. 


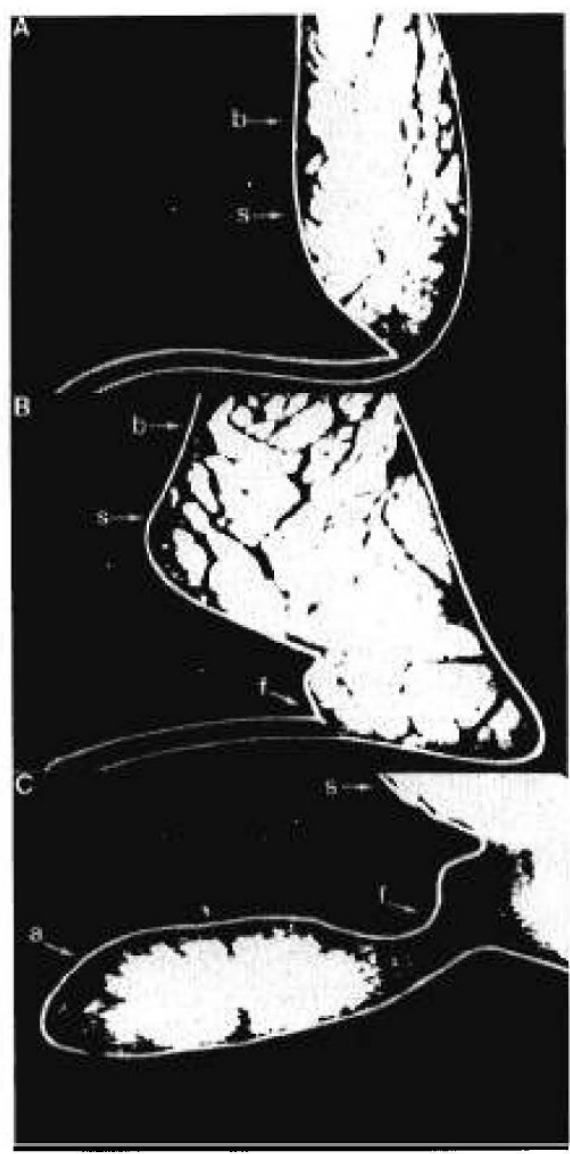

Fig. 3. Photographs from intravital microscopy of a neonate. On the figures the outline of the lumen of the CDJ is illustrated by the white lines. Incomplete contraction $(A)$ of the SDC resulted in retrograde flow of bile during ampullary contraction and the lumen of the SDC gradually filled forming a triangular shape $(B)$ before the bile flowed around the fold $(f)$ into the ampulla $(C) . s$, sphincter ductus choledochi; $a$, ampulla; $f$, fold separating SDC and ampulla; $b$, bile duct.

Contractions of structures resulted in segmental reduction of luminal diameter. When contractions completely obliterated the lumen of a structure, there was no fluorescence in the lumen. In contrast, respiratory movements (30-50 breaths/min) were more frequent than biliary contractions $(<10$ contractions/min) and moved the entire biliary tract and adjacent tissues, but unlike biliary contractions did not alter the diameter of the bile duct's lumen. Thus, respiratory movements were easily distinguished from biliary contractions.

Biliary manometry was attempted in 20 guinea pigs weighing 250 to $500 \mathrm{~g}$, but successfully completed in only five guinea which weighed $>350 \mathrm{~g}$. Six animals weighed $<350 \mathrm{~g}$. Failure was due to technical complications which included obstruction of the bile duct by the catheters, perforation of the duct, and loss of motility due to manipulation of the duct. Thus, this technique was used to confirm motility patterns observed during intravital microscopy in the older guinea pigs, but could not be used to confirm intravital microscopic data in neonates.

In five guinea pigs, biliary manometry documented frequencies and durations of SDC $(5.2 \pm 0.8$ contractions $/ \mathrm{min} ; 3.6 \pm$ $0.5 \mathrm{~s} /$ contraction) and ampullary $(1.6 \pm 0.3$ contractions $/ \mathrm{min}$; $1.4 \pm 0.4 \mathrm{~s} /$ contraction) contractions which were similar to those determined by intravital microscopy (Fig. 5). Ampullary contractions occurred only with SDC contractions. The pressures during contractions were $20 \pm 6 \mathrm{~cm} \mathrm{H}_{2} \mathrm{O}$ for the SDC and $16 \pm$ $3 \mathrm{~cm} \mathrm{H}_{2} \mathrm{O}$ for the ampulla above atmospheric pressure. Following ampullary contractions with associated SDC contraction, both

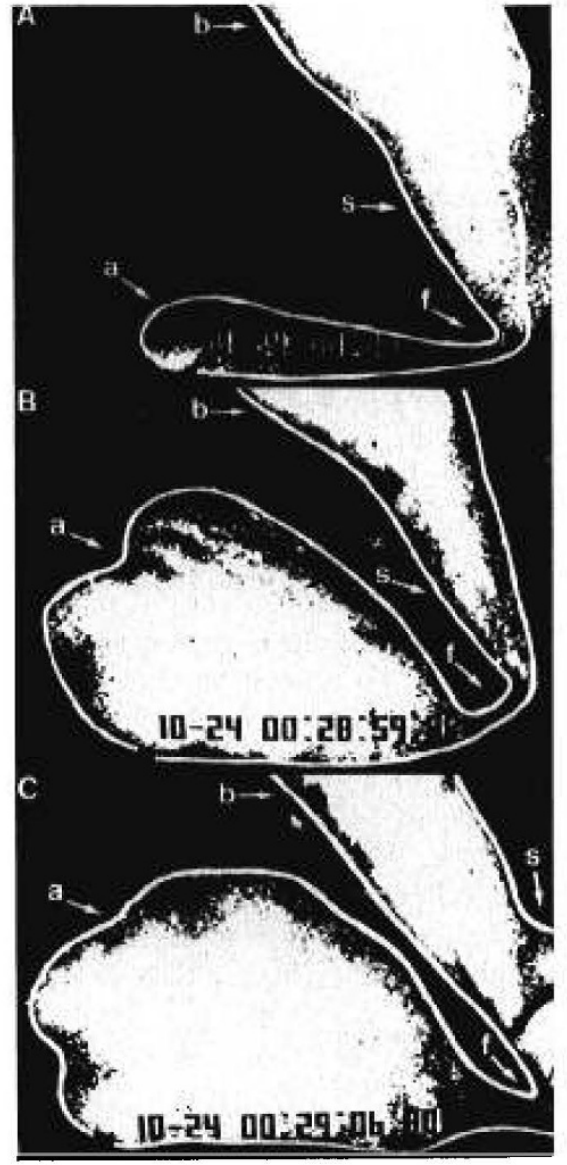

Fig. 4. Photographs from intravital microscopy of a juvenile guinea pig. On the figures the outline of the lumen of the CDJ is illustrated by the white lines. The SDC was closed during ampullary contractions preventing retrograde flow of bile $(A)$, often contracted when there were no ampullary contractions $(B)$, and allowed bile to gradually fill the ampulla between contractions $(C)$. $s$, sphincter ductus choledochi; $a$, ampulla; $f$, fold separating SDC and ampulla; $b$, bile duct.

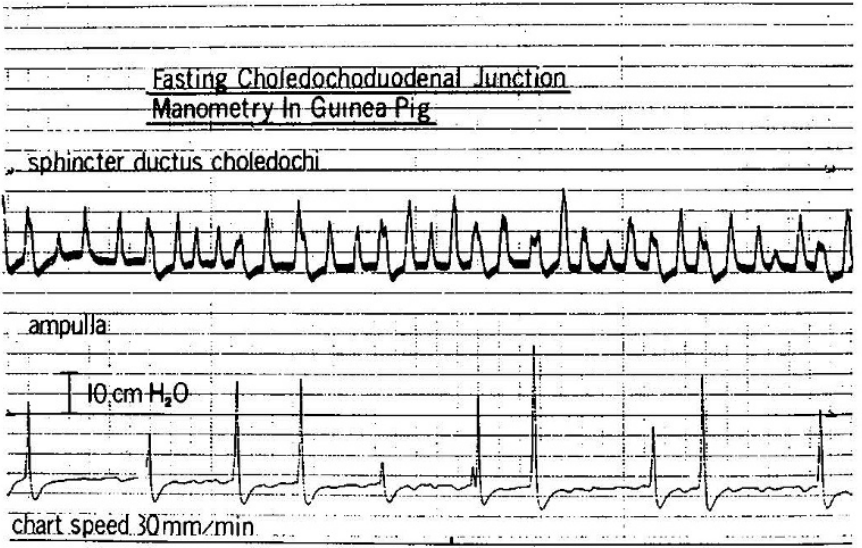

Fig. 5. Fasting biliary manometry. Water perfused $(0.07 \mathrm{ml} / \mathrm{min})$ catheters $(0.28 \mathrm{~mm}$ internal diameter) were positioned with the side opening of one catheter in the SDC and the other in the ampulla.

SDC and ampullary pressures fell $4.2 \pm 0.8 \mathrm{~cm} \mathrm{H}_{2} \mathrm{O}$ below its basal (relaxed) pressure. Sphincter pressure did not fall below its basal pressure when the SDC contracted independent of ampullary contractions.

There were no significant differences $(\mathrm{F}<1$ and $p>0.5$ for all three groups) in the volumes of bile collected during each 10- 


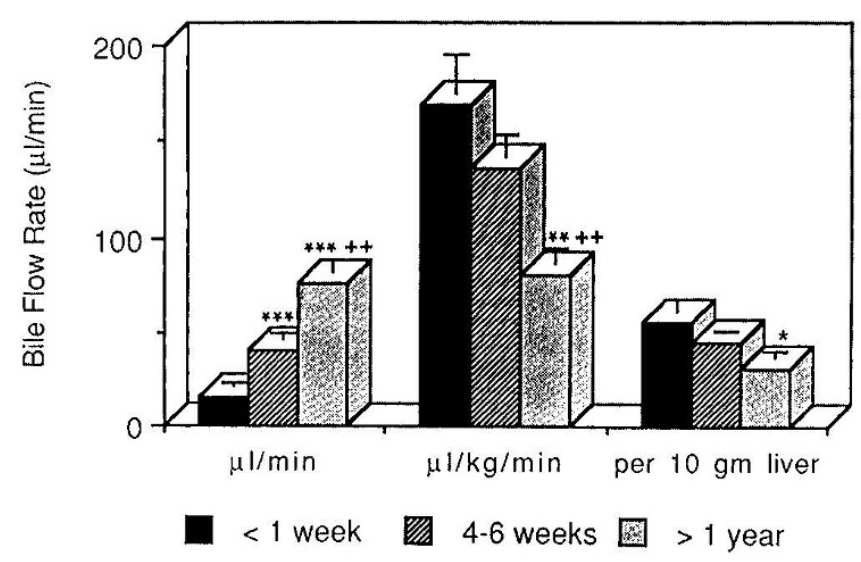

Fig. 6. Age-dependent fasting bile flow rates independent of weight $(\mu \mathrm{l} / \mathrm{min})$, per body weight $(\mu \mathrm{l} / \mathrm{kg} / \mathrm{min})$, and per liver weight $(\mu \mathrm{l} / 10 \mathrm{~g}$ liver/min). Each bar represents the mean value ( \pm SEM) for $1 \mathrm{~h}$ for 10 animals in the neonatal and adult age groups and 20 animals in the juvenile group. ${ }^{*} p<0.05,{ }^{* *} p<0.01,{ }^{* * *} p<0.001$ compared to the neonate; ${ }^{+} p<0.001$ compared to the juveniles.

min interval for $1 \mathrm{~h}$. Flow rates increased with aging. However, rates per body weight were decreased in the adult as compared to the younger animals (Fig. 6). These differences were less when calculating bile flow rates per $10 \mathrm{~g}$ of liver with the neonate and juvenile rates being similar. The diameter of the bile duct with the cannula in place did not change indicating that the catheter had not obstructed the flow.

\section{DISCUSSION}

The results of these studies demonstrated age-dependent changes in CDJ motility in guinea pigs. In the newborn, we observed decreases in frequencies of SDC and ampullary contractions and unresponsiveness of the SDC to meal stimulation. Like the human, the guinea pig is relatively mature at birth $(25$, 26). However, the muscle and mucosa of the SDC in the guinea pig is not fully developed at birth (22). Thus, hypomotility in the $\mathrm{CDJ}$ of the neonate was most likely due to its incomplete structural development.

Since bile flow rates per body and liver weights were comparable for the newborn and older guinea pigs, differences in motility were clearly not secondary to alterations in bile flow. Using indocyanine green biliary excretion, Hwang and Dixon (27) also showed no significant differences in rates of bile flow in neonatal guinea pigs compared to adults. In contrast, the dog has a gradual increase in bile flow rate within the first few weeks postnatally (28). An immature process of bile acid dependent and independent canalicular secretions and ductular reabsorption of water has been considered a principle cause of this decrease in bile flow rates in neonatal dogs. Since, unlike the dog, the very high bile flow rate of guinea pigs is largely independent of bile acid secretion, the guinea pig may not exhibit these maturational changes in bile flow rates (29).

During the 1st wk of life in the guinea pig, there was a spectrum of motility patterns from complete absence of motility to normal motility except for decreased frequencies; this indicates different rates of maturation. By $4 \mathrm{wk}$ of age, the adult CDJ motility pattern was present in all animals.

In man, dog, and opossum, intraluminal biliary manometry, electromyography, and/or cineradiography have demonstrated rhythmic phasic contractions in the CDJ which are propagated toward the duodenum and distinctly independent of duodenal motility $(31-37)$. Like the opposum, the CDJ in the guinea pig served as a pump that actively emptied its luminal contents into the duodenum and the bile duct above this junction did not exhibit contractions (37). Unlike other species, the guinea pig had rhythmic phasic contractions in the proximal CDJ (SDC) which were not propagated through the distal junction (ampulla) (Fig. 5). The varying responses of the SDC and ampullary motility to meal and hormonal (CCK, pentagastrin, secretin) stimulation suggest that these two components of the CDJ have different regulatory mechanisms (23).

We postulate that hypomotility of the CDJ in neonates effects the delivery of bile to the duodenum. In guinea pigs which are $\geq 4$ wk of age, the SDC regulated the direction of bile flow and prevented retrograde of bile flow during ampullary contractions. In the neonate, the SDC and ampulla contracted infrequently and the failure of the SDC to close completely allowed retrograde flow of bile during ampullary contractions. Thus, unlike older guinea pigs, the pumping activity of the CDJ in neonates was diminished or absent which may decrease the amount of bile pumped into the duodenum and, therefore, contribute to physiologic cholestasis and reduced amounts of intraduodenal bile acids $(1-7)$.

In our study, intravital microscopy was a sensitive, in vivo technique which quantitated the complex motility pattern of the biliary tract of guinea pigs. Unlike other techniques such as manometry, cineradiography, and electromyography, intravital microscopy may be used in very small animals, avoids manipulations of biliary structures which may produce artifacts, and does not expose animals and investigators to radiation. Biliary manometry, the "gold standard" for motility studies, is limited by the artifacts produced by the catheters $(34,37)$. Small diameter catheters $(<0.3 \mathrm{~mm})$, needed for studying animals weighing less than $0.5 \mathrm{~kg}$, have high resistance to fluid flow artificially blunting pressure measurements (37). Larger diameter catheters obstruct the lumen increasing baseline pressure, amplitude of contractions and frequency of contractions, and abolish bile flow (34). Therefore, this new approach, intravital microscopy, is well suited for quantitating biliary motility in small animals such as the neonatal guinea pig.

In conclusion, intravital microscopy demonstrated age-dependent changes in CDJ motility. We postulate that in the neonate the absent or diminished pumping function of the CDJ contributes to physiologic cholestasis and reduced amounts of intraduodenal bile acids (1-7). A possible pathogenic mechanism for biliary tract disease would be factors, such as microorganisms, drugs, and special diets, adversely affecting postnatal maturation of the CDJ $(38-40)$.

Acknowledgment. The authors thank Andrea Bettendorff for assistance with the illustrations.

\section{REFERENCES}

1. Javitt NB 1976 Cholestasis in infancy. Status report and conceptual approach. Gastroenterology 70:1172-1181

2. Erlinger $\mathrm{S} 1982$ Does $\mathrm{Na}^{++} \mathrm{K}^{+}$ATPase have any role in bile secretion? Am J Physiol 243:423-427

3. Belknap WM, Balistreri WF, Suchy FJ, Miller PC 1981 Physiologic cholestasis. II. Serum bile acid levels reflect the development of the enterohepatic circulation in rats. Hepatology 1:613-616

4. Yousef IM, Tuchweber B 1982 Bile acid composition in neonatal life in rats. Biol Neonate 42:105-112

5. Javitt NB 1976 Hepatic bile formation. N Engl J Med 295:1464-1469

6. Suchy FJ. Balistreri WF. Henbi JE, Searcy JE, Levin RS 1981 Physiologic cholestasis: evaluation of primary bile acid concentration in normal infants. Gastroenterology 80:1037-1041

7. Watkins JB, Ingall D, Szczepanik P, Klein PD, Lester R 1973 Bile-salt metabolism in the newborn. Measurement of pool size and synthesis by stable isotope technic. N Engl J Med 288:431-434

8. Lester R 1980 Physiologic cholestasis. Gastroenterology 78:864-865

9. Barbara L, Lazzari R, Roda A, Aldini R, Festi D, Sama C, Morselli AM, Collina A, Bazzoli F. Massella G, Roda E 1980 Serum bile acids in newborns and children. Pediatr Res 14:1222-1225

10. Stacey NH, Klaassen CD 1979 Uptake of ouabain by isolated hepatocytes from livers of developing rats. J Pharmacol Exp Ther 211:360-363

11. Gustafsson JA, Stenberg S 1971 Steroids in meconium from male and female newborn infants. Eur J Biochem 22:246-256 
12. Deleze G, Paumgartner G, Karlaganis G, Giger W, Reinhard M Sidiropoulos D 1978 Bile acid pattern in human amniotic fluid. Eur J Clin Invent 8:4145

13. Back P. Walter K 1980 Developmental pattern of bile acid metabolism as revealed by bile acid analysis of meconium. Gastroenterology 78:671-676

14. Hazelwood CAD 1967 Bile Salts, Methuen and Co. London

15. Watkins JB 1985 Lipid digestion and absorption. Pediatrics 75:151-156

16. Little JM, Lester R. 1981 Ontogenesis of intestinal bile salt absorption in the neonatal rat. Am J Physiol 239:319-323

17. Heird WC. Schwarz SM, Hansen IH 1984 Colostrum-induced enteric mucosal growth in beagle puppies. Pediatr Res 18:512-515

18. Watkins JB, Jarvenpaa A-L, Szczepanik-Van Leeuwen P, Klein PD, Rassin DK, Gaull G. Raiha NCR 1983 Feeding the low-birth weight infant: V. Effects of taurine, cholesterol, and human milk on bile acid kinetics. Gastroenterology 85:793-800

19. Denehy C, Ryan JP 1982 Age related changes in gallbladder motility. Fed Proc 41:1491(abstr)

20. Kaplan GS. Bhutani VK, Shaffer TH, Tran N. Koslo RJ, Wolfson MR 1984 Gallbladder mechanics in newborn piglets. Pediatr Res 18:1181-1184

21. Scherle W 1970 A simple method for volumetry of organs in quantitative stereology. Mikroskopic 26:57-67

22. Lohse CL, Cox KL. Cheung ATW, Negulesco JA 1986 The effects of growth and maturation on biliary structures of guinea pigs. Acta anat (in press)

23. Cheung ATW, Cox KL. Miller ME, Walsh EM 1986 Fluorescence intravital microscopy: a new approach for in vivo investigations. Biotechnology 4:346349

24. Cox KL. Cheung ATW 1986 Bile flow rates and biliary motility quantitated by intravital microscopy. Biomater Med Devices Artif Organs (in press)

25. Heubi JE, Fondacaro JD 1982 Postnatal development of intestinal bile salt transport in the guinea pig. Am J Physiol 243:G189-G194

26. Lt JR, Dinh DM. Ellefson RD, Subbiah MTR 1979 Sterol and bile acid metabolism during development. 3. Occurrence of neonatal hypercholesterolemia in the guinea pig and its relation to bile and pool. Metabolism 28:151-156

27. Hwang SW. Dixon RL 1973 Perinatal development of indocyanine green biliary excretion in guinea pigs. Am J Physiol 225:1454-1459
28. Tavoloni N, Jones MJT, Berk PD 1985 Postnatal development of bile secretory physiology in the dog. J Pediatr Gastroenterol Nutr 4:256-267

29. Deleted in proof

30. Cornelius CE 1976 Rates of choleresis in various species. Am J Dig Dis 21:426428

31. Toouli J, Roberts-Thomson IC, Dent J, Lee J 1985 Manometric disorders in patients with suspected sphincter of Oddi dysfuncton. Gastroenterology 88:1243-1250

32. Csendes A, Kruse A, Funch-Jensen P, Oster MJ, Ornsholt J, Amdrup E 1979 Pressure measurements in the biliary and pancreatic duct systems in controls and in patients with gallstones, previous cholecystectomy, or common bile duct stones. Gastroenterology 77:1203-1210

33. Geenen JE, Hogan WJ, Dodds WJ, Stewart ET, Arndorfer RC 1980 Intraluminal pressure recording from the sphincter of Oddi. Gastroenterology 78:317-324

34. Funch-Jensen P, Kraglund K, Djurhuss JC 1984 The influence of measuring catheter diameter on direct manometry in the canine sphincter of Oddi. Scand J Gastroenterol 19:926-930

35. Miranda M, Espinoza M, Csendes A 1981 Manometric characteristics of the extrahepatic biliary tract in dogs. Dig Dis Sci 26:417-422

36. Funch-Jensen P, Stodkilde-Jorgensen H, Kraglund K, Lovgreen NA 1981 Biliary manometry in dogs. Digestion 22:89-93

37. Toouli J, Dodds WJ, Honda R, Sarna S, Hogna WJ, Komarowski RA, Linehan $\mathrm{JH}$, Arndorfer RC 1983 Motor function of the opossum sphincter of Oddi. $\mathrm{J}$ Clin Invest 71:208-220

38. Landing $\mathrm{BH} 1974$ Consideration of the pathogenesis of neonatal hepatitis, biliary atresia, and choledochal cyst: the concept of infantile obstructive cholangiopathy. Prog Pediatr Surg 6:113-139

39. Bangaru B, Morecki R, Glaser J, Gartner LM, Horwitz MS 1980 Comparative studies of biliary atresia in the human newborn and rheovirus-induced cholangitis in weanling mice. Lab Invest 43:456-462

40. Yamashiro Y, Miyano T, Suruga K, Shimomura H, Suda K, Matsumoto M, Nittono H 1984 Experimental study of the pathogenesis of choledochal cyst and pancreatitis, with special reference to the role of bile acids and pancreatic enzymes in the anomalous choledocho-panreatico ductal junction. $J$ Pediatr Gastroenterol Nutr 3:721-727 